\title{
INVESTIGAÇÃO SOBRE O DESCARTE DE RESÍDUOS SÓLIDOS DE SAÚDE (RSS) EM UMA INSTITUIÇÃO PÚBLICA HOSPITALAR DO MUNICÍPIO DE SANT'ANA DO LIVRAMENTO - RS
}

\author{
Data de submissão: 10/10/2017 \\ Aceite: 17/07/2018 \\ Cristiane Ferreira de Souza Araujo ${ }^{1}$ \\ Mari Eldionara Rosa Machado 2 \\ Paola Rosano Rodrigues ${ }^{3}$ \\ Angela Andressa Rodrigues Fialho ${ }^{4}$
}

\section{RESUMO}

Este artigo foi pensado com a finalidade de aprimorar estudos no campo de descarte de resíduos sólidos de saúde em uma instituição pública hospitalar do município de Sant’Ana do Livramento. Para obtenção dos resultados, foi desenvolvida uma pesquisa de orientação qualitativa, realizando entrevistas estruturadas com dois responsáveis pelos setores que envolvem o lixo hospitalar da instituição. As respostas das entrevistas serviram de embasamento teórico para análises e resultados, sendo que os objetivos da pesquisa foram atingidos, principalmente com relação à identificação da política adotada pela instituição hospitalar quanto aos resíduos sólidos da saúde.

Palavras-chave: resíduos sólidos da saúde, lixo hospitalar, meio ambiente, descarte consciente.

\footnotetext{
1 Possui graduação em Letras - Língua Portuguesa pela Universidade Luterana do Brasil, ULBRA e graduação em andamento em Administração pela Universidade Federal do Pampa, UNIPAMPA, especialização em Gestão da cadeia de Suprimentos e mestrado em andamento em Administração pela UNIPAMPA. Sant'Ana do Livramento - Rio Grande do Sul. Brasil. E-mail: cris.araujo88@yahoo.com.br 2 Possui graduação em Administração pela Universidade Federal de Santa Maria, UFSM e mestrado em Administração pela UFSM. Sant'Ana do Livramento - Rio Grande do Sul. Brasil. E-mail: marimachado@unipampa.edu.br

3 Possui graduação em Administração pela Universidade Federal do Pampa, UNIPAMPA e especialização em Gestão de Recursos Humanos pelo Centro Universitário Internacional. Sant'Ana do Livramento-Rio Grande do Sul. Brasil. E-mail: paolarosano@outlook.com 4 Possui graduação em Administração pela Universidade Federal do Pampa. Sant'Ana do Livramento - Rio Grande do Sul. Brasil. E-mail: andressafialho@hotmail.com
} 


\section{INTRODUÇÃO}

Atualmente, a discussão em torno de ações sobre preservação ambiental é cada vez mais persistente, no sentido de que toda e qualquer atividade organizacional deve prestar esclarecimentos ao Estado sobre a destinação dos resíduos que produz. Percebe-se ainda, no entanto, certa negligência por parte dos profissionais que gerenciam essas organizações e empresas, que de modo geral contribuem para a poluição e a degradação do meio ambiente. Apesar disso, conforta-nos entender que a estrutura da legislação brasileira está consolidada tanto para a prevenção quanto para a manutenção da ordem geral da preservação do meio ambiente.

Ainda que existam diferentes formas de manejo sustentável de resíduos sólidos, optamos por analisar os processos de geração e de descarte dos resíduos sólidos gerados por um hospital público brasileiro. Esta escolha justifica-se pelo fato de que as instituições que promovem a saúde preventiva e curativa da população têm enorme responsabilidade com o produto gerado e com a sua destinação, uma vez que, segundo Naime, Ramalho e Naime (2008), os impactos ambientais ocasionados pelo gerenciamento inadequado dos resíduos hospitalares podem acarretar graves consequências para o meio ambiente e para a população, desde contaminações até a geração de epidemias e endemias.

O gerenciamento dos RSS é considerado um assunto polêmico e deveras discutido, considerando os riscos e os problemas que a manipulação inadequada pode causar ao meio ambiente e à saúde humana. De acordo com Silva e Rampelotto (2012), a reciclagem do lixo é fundamental para a preservação do meio ambiente: além de diminuir a extração de recursos naturais, ela reduz o consumo de energia, diminuindo também o acúmulo de resíduos produzidos. Esses autores comentam ainda sobre a crescente instalação de usinas e indústrias de reciclagem, as quais dão a correta destinação aos materiais recicláveis, contribuindo com a proteção ambiental.

Isto posto, devemos observar também o trabalho das cooperativas e dos catadores individuais, os quais "reviram" as bolsas de lixo à procura de material reciclável, podendo ferir-se com materiais perfurocortantes e contaminar-se com produtos químicos e radioativos utilizados nessas instituições. Dessa forma, as questões ambientais referentes à gestão dos resíduos sólidos hospitalares mostraram-se extremamente importantes, pois envolvem não somente a questão ambiental propriamente dita, mas também toda uma conjuntura social.

No Brasil, é possível observar inúmeras cidades que apresentam práticas inadequadas para a gestão de resíduos sólidos hospitalares, desde a segregação até o descarte final (FILHO et al., 2010). O Conselho Nacional do Meio Ambiente (CONAMA), em sua resolução no 358/05, que dispõe sobre o tratamento e a disposição final dos resíduos dos serviços de saúde e dá outras providências, define claramente quem pode produzir e o local de produção desses tipos de resíduos:

Os resíduos de serviço de saúde (RSS) são gerados em todos os serviços relacionados ao atendimento à saúde humana ou animal, inclusive serviços de assistência domiciliar e de trabalhos de campo; laboratórios analíticos de produtos para saúde, necrotérios, funerárias; serviços de medicina legal; drogarias e farmácias; estabelecimentos de ensino e pesquisa na área da saúde; centros de controle de zoonoses; importadores, distribuidores de produtos de materiais diagnósticos, dentre outros similares (CONAMA, 2005).

Dessa forma, observamos que a grande produção desses resíduos e o gerenciamento inadequado são parte de uma problemática que traz efeitos deletérios tanto para a saúde ambiental quanto para a populacional (SILVA; HOPPE, 2005), justificando, então, a escolha do tema abordado nesta pesquisa. Sendo assim, pensamos no seguinte problema de pesquisa: o método 
de gerenciamento de resíduos sólidos da saúde utilizado pela instituição hospitalar em estudo está adequado minimamente aos critérios que a legislação propõe?

No intuito de responder a essa questão, elaboramos o seguinte objetivo geral: identificar se há e qual é a política adotada pela instituição hospitalar no que tange ao gerenciamento dos resíduos sólidos da saúde, verificando se correspondem minimamente ao exigido pela legislação. Como objetivo específico, buscamos identificar: se existe a adoção de um programa de destinação de RSS; qual o método de segregação dos resíduos sólidos da saúde no momento em que são produzidos; de que forma é realizada a destinação dos resíduos sólidos da saúde produzidos pela instituição; qual o nível de informação e de conhecimento dos funcionários responsáveis pela coleta e destinação do lixo a respeito do impacto ambiental que o descarte inadequado pode causar ao meio ambiente.

Segundo Pereira e Pereira (2011), para que haja a compreensão da cadeia de produção de resíduos e seu manejo de forma sustentável e segura, numa perspectiva de ganho econômico e promoção da saúde coletiva, é preciso adotar o gerenciamento logístico, de modo a contemplar as variáveis pertinentes. O Conselho Nacional do Meio Ambiente (CONAMA), em suas resoluções de $n$ ㅇ 238/01 e 358/05, estabelece que, para qualquer estabelecimento produtor de RSS funcionar, é necessário um processo de licenciamento ambiental que envolve a produção de um Plano de Gerenciamento de Resíduos de Saúde (PGRSS), especificando quais são os resíduos produzidos, qual o manuseio, qual o tipo de coleta interna, de acondicionamento, de coleta externa, além de outras informações pertinentes ao estabelecimento de saúde.

De acordo com Moura e Meotti (2011), esse tipo de lixo é subdividido em cinco grupos, o que torna a sua separação extremamente complexa para muitos profissionais da área da saúde responsáveis por ela. Para que seja garantido o descarte correto, existem normas na Resolução no 306/04 da Agência Nacional de Vigilância Sanitária (ANVISA), e na no 358/05 do Conselho Nacional do Meio Ambiente (CONAMA), as quais servirão como base para a análise dos resultados desta pesquisa.

\section{REFERENCIAL TEÓRICO}

\subsection{RESÍDUOS SÓLIDOS DA SAÚDE}

Torna-se necessário, então, compreender de que forma os estabelecimentos de saúde lidam diariamente com o "lixo" ou com os "resíduos" que produzem. Entende-se que as respostas a esses questionamentos devem estar nos processos executados pelos profissionais responsáveis pelo setor e operários; entretanto, observa-se que muito contribuiria se a cultura organizacional estivesse enraizada a essas técnicas operacionais e valores ambientais.

De acordo com Gessner et al. (2013), é necessário que os profissionais da área de saúde enfrentem essa problemática desenvolvendo competências e habilidades específicas já na graduação. Para esses autores, trata-se de um conhecimento técnico-científico imprescindível para a formação de profissionais éticos e responsáveis, dada a amplitude das questões que envolvem a produção e o gerenciamento dos Resíduos Sólidos da Saúde (RSS). Assim, compreende-se a formação do profissional como parte fundamental no processo de assimilação e de comprometimento com as causas ambientais, pois essa temática exige comportamentos éticos e morais estruturados de forma contundente.

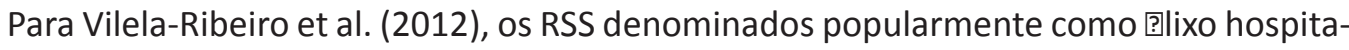
lar? são aqueles produzidos em unidades de saúde, constituídos de lixo comum e de resíduos in- 
fectantes ou de risco. Esses lixos possuem um grau de periculosidade, sendo o descarte correto o mínimo a se fazer para amenizar os riscos. Coelho (2001) afirma que os resíduos sólidos de serviços, como aqueles gerados por prestadores de assistência médica, fazem parte de todas as áreas relacionadas ao atendimento populacional, incluindo a veterinária. Segundo ele, os resíduos que oferecem riscos - como objetos perfurocortantes, contaminados, produtos químicos perigosos, entre outros - necessitam de cuidados específicos, desde o acondicionamento, o transporte, 0 armazenamento, a coleta, o tratamento até a disposição final. Essa esfera é amparada pela Lei $\mathrm{N}^{\circ}$ 12.305/2010, intitulada Lei de Resíduos Sólidos, como mecanismo de fomento à sustentabilidade ambiental no âmbito dos resíduos/rejeitos gerados pela produção e pelo consumo das pessoas, atribuindo aos seus produtores a responsabilidade pelo descarte adequado dos lixos.

Na concepção de Oliveira (2002), a atividade hospitalar é um amplo gerador de resíduos. Sendo assim, conforme Moura e Viriato (2008), o maior objetivo do gerenciamento dos resíduos sólidos é minimizar os riscos à saúde da população interna e externa do estabelecimento da saúde. Esses autores apontam também que, devido à grande diversidade de estabelecimentos relacionados à saúde, torna-se inviável estabelecer parâmetros quanto à produção de RSS. Para Carramenha (2005), os resíduos provenientes da prestação de serviços de saúde a seres vivos (humanos e animais), incluindo todas as atividades médicas de prevenção, diagnósticos, tratamento e análise, têm por objetivo prevenir possíveis impactos que possam afetar a população e o meio ambiente.

De acordo com a Resolução no 358 do CONAMA (2005), os resíduos da área de saúde são agrupados da seguinte forma:

GRUPO A: resíduos com a possível presença de agentes biológicos que, por suas características de maior virulência ou concentração, podem apresentar risco de infecção. Esse grupo divide-se em A1 (descarte de vacinas de microorganismos, bolsas transfusionais, resíduos laboratoriais), A2 (resíduos provenientes de animais), A3 (peças anatômicas de ser humano), A4 (filtros de ar e gases aspirados de área contaminada, resíduos de tecido adiposo), A5 (Materiais perfuro cortantes provenientes de seres contaminados com príons);

GRUPO B: resíduos que contenham substâncias químicas que podem apresentar risco à saúde pública ou ao meio ambiente, dependendo de suas características de inflamabilidade, corrosividade, reatividade e toxicidade. Nesse grupo, encontram-se os produtos hormonais, produtos antimicrobianos, imunomoduladores, resíduos e insumos farmacêuticos dos medicamentos controlados, resíduos de saneantes, desinfetantes, resíduos contendo metais pesados; reagentes para laboratório, inclusive os recipientes contaminados por estes;

GRUPO C: todo material resultante de atividades humanas que contenham radionuclídeos em quantidades superiores aos limites de eliminação especificados nas normas da Comissão Nacionalde Energia Nuclear - CNEN, para os quais a reutilização é imprópria ou não prevista. Fazem parte desse grupo quaisquer materiais resultantes de laboratórios de análises clínicas, nuclear e radioterapia que contenham radionuclídeos em quantidade superior aos limites de eliminação;

GRUPO D: resíduos que não apresentem risco biológico, químico ou radiológico à saúde ou aomeio ambiente, podendo ser equiparados aos resíduos domiciliares. Enquadram-se nesse grupo papel de uso sanitário e fralda, resto alimentar de paciente, material utilizado em anti-sepsia, equipo de soro, resíduos provenientes das áreas administrativas, resíduos de varrição, jardins, resíduos de gesso provenientes de assistência à saúde;

GRUPO E: resíduos perfurocortantes ou escarificantes, tais como: lâminas de barbear, agulhas,escalpes, ampolas de vidro, limas endodônticas, lâminas de bisturi, lancetas; tubos capilares,micropipetas; lâminas e lamínulas, espátulas, e os utensílios de vidro quebrados no laboratório. 
Ainda segundo essa resolução, o gerenciamento dos resíduos sólidos, desde a geração até a disposição final, de forma a atender aos requisitos ambientais e de saúde pública e saúde ocupacional, é de responsabilidade dos estabelecimentos prestadores de serviços de saúde. A resolução também aponta não haver prejuízo de responsabilização solidária de pessoas físicas e jurídicas que, direta ou indiretamente, causem ou possam causar degradação ambiental, em especial os transportadores e os operadores das instalações de tratamento e disposição final.

Torna-se necessário, então, que o estabelecimento de saúde proporcione o manuseio seguro dos resíduos, uma vez que essa operação envolve risco potencial de acidente, principalmente para os profissionais que atuam diretamente nas etapas de gerenciamento (CUSSIOL, 2008). É estabelecido pela Constituição Brasileira que a limpeza pública, a coleta, o transporte e a disposição de resíduos sólidos são responsabilidades da União, dos Estados e do Distrito Federal, cabendo a eles legislar sobre a defesa e a proteção à saúde. Apesar disso, os municípios possuem autonomia para criar as suas próprias leis e são os responsáveis pela coleta e fins do RSS (BRASIL, art. 24, 1988).

Segundo as Resoluções RDC 306/2004 da ANVISA e 358/2005 do CONAMA, todo gerador de RSS deve elaborar um Plano de Gerenciamento de Resíduos de Serviços de Saúde (PGRSS) baseado nas características dos resíduos gerados e na classificação existente, estabelecendo as diretrizes de manejo dos RSS. O PGRSS deve ser compatível com as normas locais relativas à coleta, ao transporte e à disposição final dos resíduos gerados nos serviços de saúde, estabelecidas pelos órgãos locais responsáveis por estas etapas.

Para Monteiro et al. (2001), um dos procedimentos mais importantes no manuseio desses resíduos consiste na separação do lixo infectante dos resíduos comuns, visto que o lixo infectante representa apenas $10 \%$ a $15 \%$ do total dos resíduos e o lixo comum não requer maior cuidado. Existem dois parâmetros que, se fossem cumpridos de modo geral, amenizariam os problemas de depósitos de lixos: o Princípio da precaução, relacionado à cautela que a população em geral deve ter em relação a qualquer tipo de resíduo, e o Princípio do poluidor pagador, relacionado ao ônus que deve ser pago pelo gerador do resíduo depositado em lugares indevidos (BRASIL, art. 225, 1988).

\subsection{RESÍDUOS SÓLIDOS DA SAÚDE E SEU IMPACTO NO MEIO AMBIENTE}

Entende-se que, além dos cuidados existentes com a manipulação e o descarte dos resíduos sólidos da saúde, torna-se imprescindível considerar o impacto desse descarte no meio ambiente. Segundo Ferreira (2000), o volume crescente de resíduos produzidos nos centros urbanos e industriais tem sido motivo de grande preocupação por parte das comunidades, dos governos, dos pesquisadores e dos ambientalistas, sendo a questão dos resíduos sólidos um dos temas centrais para aqueles que se preocupam com o meio ambiente.

De fato, muitas substâncias químicas e muitas formas de resíduos resultam em substâncias nocivas que representam perigos para a nossa vida e para a natureza que nos rodeia (PNUMA, 2017). Frente a isso, Silva e Rampelotto (2012) afirmam que a questão dos resíduos sólidos hospitalares caracteriza um dos fatores mais complexos da atualidade e que buscar soluções para essa problemática, começando na base de geração desses refugos, é um gesto de cidadania. Assim, é de importância ímpar minimizar os riscos patológicos à saúde humana através do manejo adequado de grandes volumes de "lixo hospitalar" que serão despejados no meio ambiente. Correa et al. (2005) salientam que é inquestionável também a implantação de políticas de gerenciamento dos RSS nos diversos estabelecimentos de saúde, não apenas investindo na organização e 
na sistematização das fontes geradoras, mas, fundamentalmente, despertando uma consciência humana e coletiva voltada à própria vida e ao ambiente.

Para Tapia (2009), é necessário ampliar a investigação sobre os efeitos ambientais na saúde humana causados pelo manejo inadequado dos resíduos, a fim de determinar o descarte apropriado para esse tipo de resíduo. Nos espaços da educação formal, sobretudo nos cursos de graduação da área de saúde, é fundamental proporcionar debates e reflexões acerca das questões ambientais e ecológicas, fazendo com que os futuros profissionais de saúde tenham uma visão global e uma conduta local (BACKES et al., 2011). A questão ambiental tem se tornado um determinante do processo saúde-doença. Com isso, é importante considerar a dimensão do meio ambiente perante as ações realizadas nos serviços de saúde, possibilitando e promovendo ações estratégicas voltadas para o (re)pensar das práticas em saúde e de suas consequentes implicações para a sustentabilidade ambiental (MORESCHI et al., 2011).

Com relação à questão ambiental brasileira dos RSS, Vilela-Ribeiro et al. (2009) apontam que dois documentos principais foram utilizados como referência básica para grande parte dos trabalhos nacionais referentes ao assunto, sendo eles: Management of waste from hospitals - WHO (1983) e EPA - Guide for infections waste management (1986) da United States Environmental Protection Agency. Os autores, entretanto, consideram esse fato um equívoco, prova da não-integração entre política e sociedade nas questões ambientais, visto que os textos apresentam alternativas solucionadoras para países desenvolvidos, investidores de grande capital para o tratamento de resíduos, características que não incluem a política brasileira de tratamento de resíduos.

Vilela-Ribeiro et al. (2009) ressaltam também a necessidade do conhecimento dessas normas e regras como ferramentas para garantir o manejo adequado dos RSS:

Assim, a geração de problemas ambientais em detrimento da falta de manejo adequado dos RSS faz o homem refletir sobre a importância de se conhecer o que deve ser feito em relação à gestão dos RSS. É interessante, portanto, o conhecimento das leis, normas, decretos e resoluções que vigoram no país a respeito do modo como as instituições que produzem RSS devem proceder na coleta, seleção, armazenamento, e descarte dos mesmos e por isso uma revisão normativa é feita, abordando-se as principais normas vigentes dos órgãos de gestão ambiental do país, além daquelas reguladoras e licenciadoras de instituições de saúde (VILELA-RIBEIRO et al., 2009).

A possibilidade de contaminação do meio ambiente, de pacientes, de funcionários e da comunidade por tais resíduos poderá ser considerada inexistente se medidas básicas de manejo e controle adequado forem devidamente aplicadas (ERDTMANN, 2004; PEREIRA, LUCENA, FERNANDES, 2010).

\section{METODOLOGIA}

O presente artigo caracteriza-se na abordagem qualitativa com caráter descritivo e exploratório. Segundo Gil (2012), as pesquisas descritivas têm como principal objetivo a definição das características de uma população, de um fenômeno ou o estabelecimento de semelhanças dentre variáveis. Quanto ao caráter da pesquisa exploratória, Gil (2012) ressalta que seu intuito é aproximar a ideia ou a visão geral sobre algum fator definido na pesquisa. Ao tratar da abordagem qualitativa, o pesquisador "não se preocupa com representatividade numérica, mas, sim, com o aprofundamento da compreensão de um grupo social, de uma organização, etc" (GERHART e SILVEIRA, 2009). 
O método utilizado neste artigo foi o estudo de caso, a fim de estudar, de forma ampla, o impacto do lixo hospitalar no ambiente. Esse método "permite que seja analisada uma situação na qual não se possam fazer interferências no sentido de manipular comportamentos relevantes; neste método os dados são coletados a partir de múltiplas fontes" (STAKE, 1978; DENZIN; LINCOLN, 2001). Nesse mesmo viés, Gil (2010) identifica que o estudo de caso não tem uma estrutura rígida, mas varia conforme os objetivos do pesquisador.

Para o levantamento das informações, foi aplicada uma entrevista estruturada, a qual, segundo Severino (2007, p. 125), contém questões direcionadas e previamente estabelecidas com determinada articulação interna, aproximando-se de um questionário, mas sem a impessoalidade deste. Foram entrevistados a funcionária, identificada pelas iniciais P. M.G., responsável pelo setor de Controle de Infecção Hospitalar $(\mathrm{CClH})$, que trata do meio ambiente na instituição em estudo, e o operário responsável pela coleta e armazenamento do lixo hospitalar, identificado pelas iniciais O. P. M. As entrevistas foram gravadas por um dispositivo móvel, sendo posteriormente redigidas e analisadas de forma minuciosa.

Para complementar o levantamento, foi feita uma pesquisa documental para analisar o Plano de Gerenciamento de Resíduos de Serviços de Saúde - PGRSS da instituição. De acordo com Severino (2007, p. 124), a pesquisa documental é toda forma de registro e sistematização de dados, colocando-os em condições de análise por parte do pesquisador. Para Gil (2012), o documento em análise consiste em documento de segunda mão, que "são documentos que de alguma forma já foram analisados, tais como relatórios de pesquisa, relatórios de empresas, tabelas estatísticas etc" (GIL, 2012, p. 51).

Para a análise de dados, foi utilizada a análise de conteúdo. Para Bardin (1977), esse tipo de análise tende a ser descritivo quando a técnica é empregada na conversação entre indivíduos, sendo que esses dados servem de base para a produção de estudos sobre o conteúdo. Esse método é definido por Berelson (1952, p.13) como "uma técnica de investigação que, através de uma descrição objetiva, sistemática e quantitativa do conteúdo manifesto das comunicações, tem por finalidade a interpretação destas mesmas comunicações".

\section{RESULTADOS}

Os resultados estão divididos, a seguir, em dois tópicos: no primeiro, foi entrevistada a responsável do setor $\mathrm{CCIH}$ e, no segundo, o operário responsável pela coleta e armazenamento dos RSS da Instituição Pública Hospitalar.

\subsection{O DESCARTE DE RSS NA INSTITUIÇÃO PÚBLICA HOSPITALAR DO MUNICÍPIO DE SANT’ANA DO LIVRAMENTO}

Na Instituição Hospitalar estudada, o plano de gerenciamento dos Resíduos de Serviços de Saúde (RSS) é armazenado através de mídia online, sendo que os responsáveis de cada setor dispõem de uma via armazenada em dispositivo eletrônico. Segundo a funcionária P. M. G., a elaboração do plano de gerenciamento seguiu os princípios propostos pelo manual estabelecido pelas normas da ANVISA (Agência Nacional de Vigilância Sanitária).

Quando questionada sobre as práticas para a redução dos RSS, a entrevistada ressalta que não há nenhuma prática visando à redução da produção de resíduos, sendo, por vezes, inevitável não utilizá-los nos procedimentos, sejam eles cirúrgicos ou rotineiros, já que estão relacionados ao 
cuidado com vidas. Da mesma forma, a reutilização é um fator inviável, pois muitas vezes são tratadas infecções e, portanto, deve-se evitar o contágio de próximos. Quanto à reciclagem, a responsável disse que, até o momento, nenhuma política foi implementada visando esse ponto.

Nessa unidade hospitalar, são produzidos diversos tipos de lixos, os quais podem ser identificados como: Tipo A (Infectantes), Tipo B (Químicos), Tipo C (Radioativos), Tipo D (Comum) e Tipo $E$ (Perfuro Cortantes). É importante apontar que nenhum dos tipos de lixos que a instituição produz recebe algum tratamento prévio interno antes de sua acondicionação. Para uma boa organização, os lixos são embalados de diferentes maneiras, a fim de que sejam identificados facilmente pelos profissionais atuantes no local.

O lixo Tipo A (Infectante) é armazenado em saco branco leitoso, identificado na imagem abaixo:

Figura 1 - Lixo Tipo A - Infectante

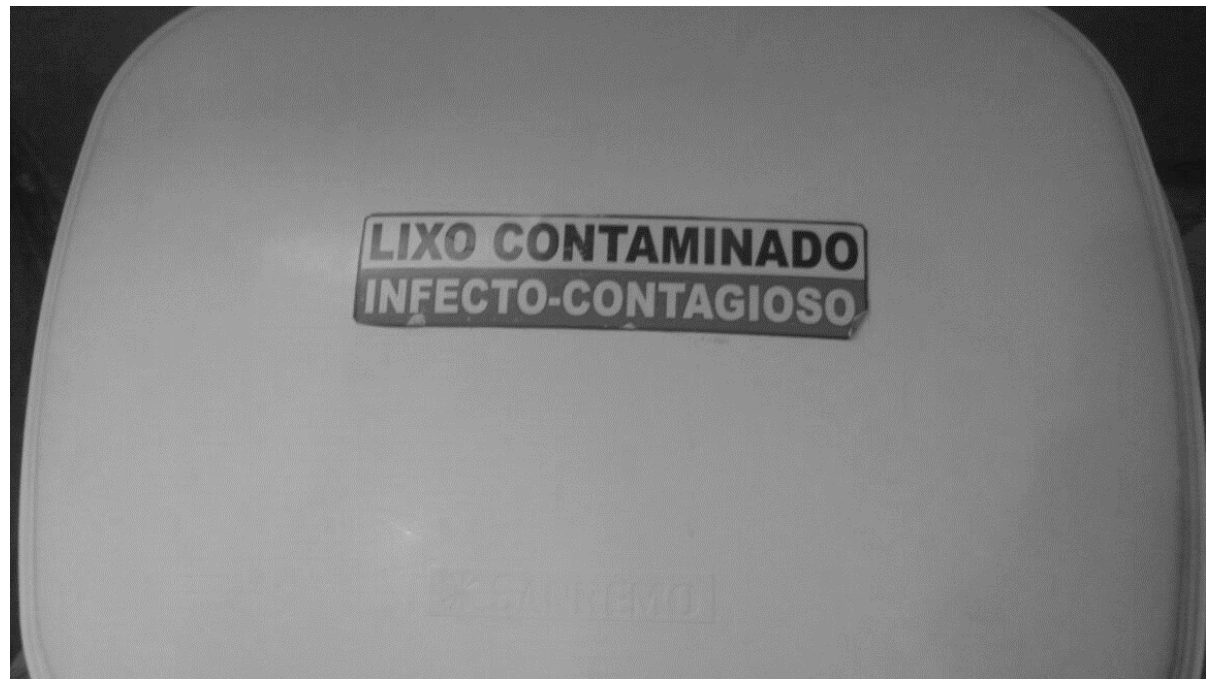

Fonte: Araújo et al. (2017).

Os lixos classificados como Tipo B, por sua vez, são compostos por medicamentos vencidos. As embalagens de soluções desinfetantes, reveladores e fixadores, entre outros, são descartados juntamente ao lixo contaminado da Figura 1, mas em embalagens separadas.

Os RSS, anteriormente à coleta para o destino final externo ao hospital, são armazenados em um local próprio destinado ao lixo hospitalar, situado nos fundos da Instituição. A esse local é dado o nome de pátio, e os resíduos são armazenados em containers para que o caminhão da empresa responsável faça a coleta. O pátio é o local exclusivo para esse descarte temporário, ao qual somente uma pessoa tem acesso: o responsável por toda a coleta da Instituição, o qual mantém o local sempre organizado.

A entrevistada, P. M. G., salientou a importância de haver diferentes containers no local, os quais servem para facilitar a identificação pelos servidores do hospital e pelos servidores da empresa externa, responsáveis pela coleta. O local é desinfetado diariamente, tanto pela instituição quanto pelo local do armazenamento dos RSS. A coleta é feita semanalmente por um caminhão compactador, que faz também a coleta de todos os órgãos que produzem lixo hospitalar e RSS na cidade de Sant'Ana do Livramento. Quando questionada sobre o custo do serviço, P. M. G. afirmou desconhecer a informação. 
A entrevistada citou também a relevância do descarte dos resíduos perfurocortantes classificados como lixos Tipo E, descartados em uma caixa denominada Descarpack, a qual pode ser visualizada na figura abaixo:

Figura 2 - Descarpack

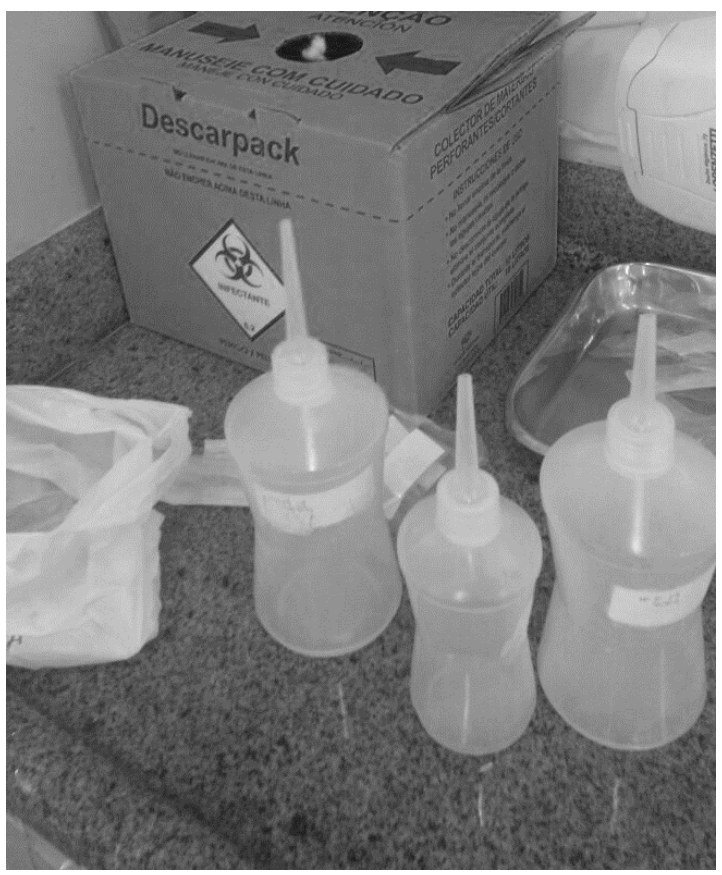

Fonte: Araújo et al. (2017).

Para evitar danos ao meio ambiente e impedir causas passíveis de poluição, a entrevistada acredita que é preciso haver o acondicionamento dos resíduos sólidos da instituição investigada de maneira adequada, visando ao bem estar da humanidade e do solo. Isso porque a contaminação acarretaria problemas como: a multiplicação de microorganismos no meio ambiente, a utilização de materiais descartados erroneamente por pessoas que circulam pelos lixões, a contaminação do solo dos lixões ou dos locais onde o lixo for descartado, e a contaminação de poços de água próximos aos lixões, infectando a água potável consumida pelos demais moradores.

Já no ambiente hospitalar, P. M. G. entende que o armazenamento incorreto pode aumentar as chances de multiplicação de bactérias e de infecções aos pacientes, além de poder contaminar e colocar em risco os funcionários que manipulam esses materiais e os visitantes que diariamente percorrem os corredores hospitalares. Assim, compreende-se que manter o ambiente hospitalar limpo e organizado é dever de todos.

\subsection{A DESTINAÇÃO DOS RESÍDUOS SÓLIDOS DE SAÚDE GERADOS NA INSTITUIÇÃO}

Para introduzir este tópico, inicialmente foram caracterizados os tipos de resíduos gerados pela Instituição Hospitalar, identificados por O. P. M. como biológicos/contaminados (ex.: algodão, gazes, luvas de procedimentos, esparadrapos e ataduras, etc.), perfurocortantes e comuns. Identificamos que são gerados aproximadamente 3.202 litros de resíduos contaminados pela Instituição por semana. Os resíduos perfurocortantes são separados em embalagens Descar- 
pack, as quais são caracterizadas por três modalidades: 03 L, 07 L, e 13 L. Não há conhecimento sobre a quantidade de lixo comum produzido porque, segundo o funcionário, ele não é pesado, visto que não há custo algum para o hospital; o lixo somente é descartado na lixeira comum e coletado pelo caminhão que faz a coleta do município.

O. P. M. apontou que todas as embalagens de acondicionamento do lixo são identificadas por símbolos ou por placas indicativas descritivas. Observou-se que, após sair do interior do hospital, o lixo é encaminhado até a parte externa identificada como pátio, onde é depositado e, posteriormente, levado ao destino final. Abaixo, a Figura 3 ilustra o pátio da instituição:

Figura 3- Lixo comum armazenado no pátio do hospital

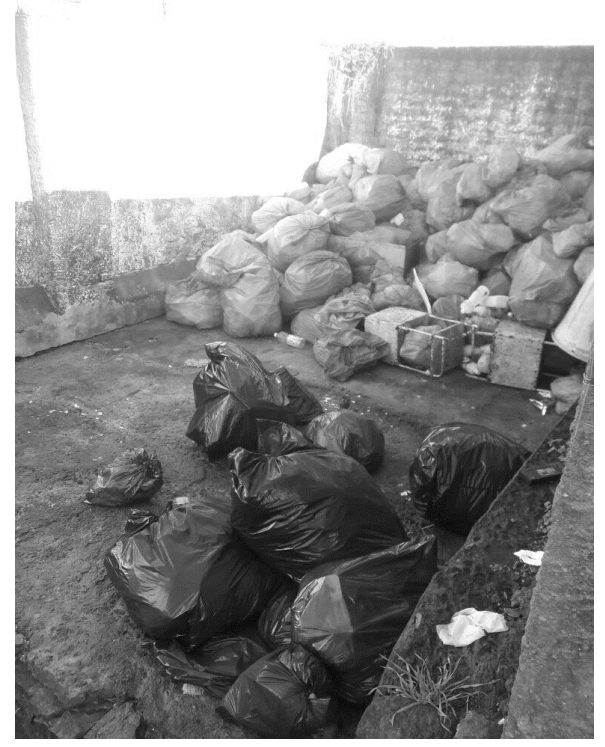

Fonte: Araújo et al. (2017).

Quanto à coleta interna dos RSS, há um funcionário da Instituição Hospitalar responsável pela coleta, a qual é feita semanalmente. Esse lixo interno é transportado em um carrinho com tampa, impedindo que os odores se espalhem pelos corredores do hospital. Quando questionado sobre o tratamento interno do lixo antes de chegar ao pátio, O. P. M. responde que não há nenhum tipo de tratamento. Quanto ao responsável pela coleta externa, o entrevistado aponta ser uma empresa especializada, mas não tem conhecimento específico sobre seu nome, apenas intuição de que seja situada na cidade de Santa Maria. Foi relatado também que o responsável da instituição não conhece o tipo de tratamento dado ao lixo, apenas acredita que o destino final seja a sua incineração.

Na visita do local junto a O. P. M., foi presenciada a condição precária em que se encontra o depósito dos RSS da Instituição Hospitalar, como aponta a Figura 4, a seguir: 
Figura 4 - Local designado para depósito de resíduos sólidos hospitalares infectantes

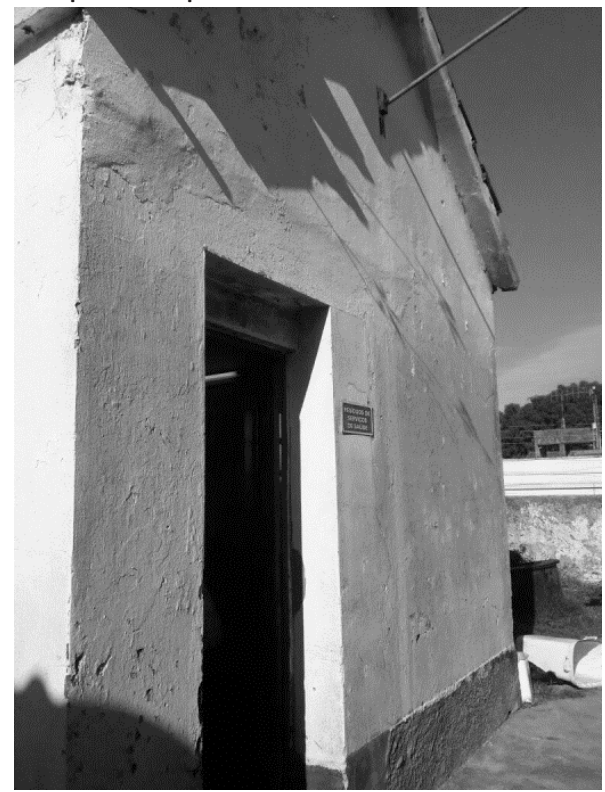

Fonte: Araújo et al. (2017).

Notou-se a existência de um freezer que armazena os dejetos humanos, bem como a de vários tonéis mal fechados, os quais causam um mau odor no ambiente e não possuem classificação nem identificação para depósito e separação dos resíduos. Isso demonstra que os resíduos separados no momento de sua geração não permanecem separados no momento do depósito e destinação, visto que estavam misturados uns aos outros. Observou-se também que, neste mesmo local, há camas hospitalares, móveis e utensílios que podem ser reutilizados pela instituição. Sendo assim, não há correspondência da medida mínima de segurança para o armazenamento e depósito de utensílios que podem ser reutilizados, uma vez que a área de depósito do lixo está muito exposta e próxima desses objetos.

Ainda que o lixo seja bem separado no momento de sua geração, quando levado para a parte externa ele é tratado de outra forma, o que contradiz a resposta dada pelo responsável do setor:

Entrevistador: Como é feito o armazenamento temporário dos Resíduos de Serviços de Saúde antes de ser coletado pelo responsável pelo transporte externo até o destino final? P.M.G: Ah, sim, eles são armazenados lá no fundo, tem... tipo um pátio, ninguém tem acesso, e o lixo é colocado em tonéis... em containers, e o que sai do bloco cirúrgico fica numa geladeira tipo um freezer, até eles virem retirar, e os outros tipos de lixo têm os seus devidos containers.

\section{CONSIDERAÇÕES FINAIS}

Com base nas informações obtidas nesse estudo, os resultados evidenciaram a complexidade do tema abordado, indicando a necessidade de uma atenção maior, já que resíduos hospitalares acondicionados em lugares inadequados podem proporcionar riscos à saúde humana e ao meio ambiente. Deve-se levar em consideração que o descarte adequado desses resíduos depende completamente de todos os envolvidos, desde aquele que os gera até aquele que os 
destina para o local adequado; assim, é necessário que todos tenham consciência e conhecimento dos malefícios que os RSS podem causar.

As entrevistas mostraram que os profissionais têm conhecimento desses riscos e agem de acordo com os procedimentos adequados, selecionando os resíduos e fazendo a desinfecção diária para evitar qualquer contaminação. Assim, identificou-se a adoção de um programa de destinação de RSS, apontando, contudo, que os funcionários desenvolvem as atividades de maneira precária e com o mínimo treinamento.

Também foi identificado um método de segregação dos resíduos sólidos da saúde no momento em que são produzidos, percebendo que, no momento da geração do resíduo, eles são devidamente separados, mas, enquanto aguardam a coleta semanal, ficam juntos indiscriminadamente. Além disso, constatou-se a forma como é realizada a destinação dos resíduos sólidos da saúde produzidos pela instituição, através de empresa terceirizada cujo nome é desconhecido pelos funcionários, o que acarreta em altos custos para a instituição.

No que se refere aos equipamentos de proteção individual, a instituição fornece-os aos funcionários que realizam a limpeza e a coleta do lixo hospitalar, visando minimizar os acidentes, devido à grande manipulação de materiais perfurocortantes e contaminados. Dessa forma, as questões ligadas à manipulação e ao descarte dos RSS não diz respeito só aos trabalhadores, mas também aos responsáveis pelo planejamento e a conscientização de todos aqueles que integram a instituição, a fim de orientá-los a manusear os resíduos de forma adequada.

Quanto à análise do nível de informação e conhecimento que os funcionários responsáveis pela coleta e destinação do lixo têm a respeito do impacto ambiental que o descarte inadequado pode causar, não foi possível completá-la, considerando que o questionário proposto foi respondido somente pelos dois funcionários apontados neste estudo e não pode representar a visão geral dos colaboradores da instituição. Notou-se, portanto, uma limitação neste estudo, já que o acesso a um grupo maior de funcionários para a realização das entrevistas não foi possível, não por parte da direção, mas por parte dos próprios funcionários, que aparentemente sentiram-se incomodados ou, de certa forma, desconfiados ao receber a proposta de pesquisa.

De modo geral, o resultado deste estudo é de bastante valia para a instituição, uma vez que, a partir deste, ela poderá propor ações de melhoria para a manutenção do local que abriga o lixo infectado, bem como organizar um depósito seguro para os móveis e utensílios expostos à intempérie. Da mesma forma, o estudo é importante para as Ciências Sociais por propor uma análise da realidade de muitas instituições hospitalares brasileiras que, por não contarem, muitas vezes, com profissionais capacitados, acabam desenvolvendo suas atividades de forma inadequada, oferecendo riscos aos seus trabalhadores, à comunidade e ao meio ambiente. 


\section{REFERÊNCIAS BIBLIOGRÁFICAS}

AGÊNCIA NACIONAL DE VIGILÂNCIA SANITÁRIA ?] ANVISA (Brasil). Resolução da Diretoria Colegiada? RDC no 306, de 07 de dezembro de 2004. Dispõe sobre o Regulamento Técnico para o gerenciamentode resíduos de serviços de saúde. Diário Oficial da União, 10 dez. 2004.

BACKES, M. T. S. et al. Do antropocentrismo ao ecologicentrismo: formação para o cuidado ecológico na saúde. Rev. Gaúcha Enferm.2011;32(2):263-9.

BARDIN, L. Análise de conteúdo. LISBOA: Edições 70, 1977.

BERELSON, B. Content Analysis. In: Communication Research. New York: University Press, 1952.

BRASIL. Constituição Federal de 1988. Promulgada em 5 de outubro de 1988. Disponível em <http:// www.planalto.gov.br/ccivil_03/constituicao/constituição.htm>Acesso em: 20 de jun. de 2017.

BRASIL. Ministério do Meio Ambiente, Conselho Nacional do Meio Ambiente, CONAMA. Resolução CONAMA no 238/2001, de 12 de julho de 2001. Disponível em: < http://www2.mma. gov.br/port/conama/res/res01/res28301.html> Acesso em: 31 de jul. de 2018.

BRASIL. Ministério do Meio Ambiente, Conselho Nacional do Meio Ambiente, CONAMA. Resolução CONAMA no 358/2005, de 29 de abril de 2005. Disponível em: <http://www.mma.gov. $\mathrm{br} /$ port/conama/legiabre.cfm?codlegi=462> Acesso em: 31 de jul. de 2018.

CARRAMENHA, M. M. L. Gerenciamento de resíduos sólidos em serviços de saúde: uma contribuição para a avaliação do desempenho ambiental. Dissertação (Mestrado em Engenharia Ambiental Urbana)- Escola Politécnica da Universidade Federal da Bahia, Salvador, 2005.

COELHO, H. Manual de gerenciamento de resíduos sólidos de serviços de saúde. Rio de Janeiro: FIOCRUZ, 2001.

CUSSIOL, N. A. de M. Manual de gerenciamento de resíduos de serviços de saúde. Belo Horizonte:Fundação Estadual do Meio Ambiente ?] FEAM, 2008.

DENZIN, N. K., LINCONLN, Y. S. The American tradition in qualitative research. 2001.

ERDTMANN, B. K. Gerenciamento dos resíduos de serviço de saúde: biossegurança e o controle das infecções hospitalares. Revista Texto \& contexto Enfermagem, Florianópolis, v.13, p. 86- 93, 2004.

FILHO, A. M. C.et al. Análise do conhecimento de profissionais da saúde, estimativa na cidade de Sítio Novo, TO, Relativo aos resíduos hospitalares. Educação Ambiental em Ação.n.31. Ano: VIII Março/ Maio 2010, online.

GESSNER, R.et al. O manejo dos resíduos dos serviços de saúde: um problema a ser enfrentado. Cogitare Enfermagem, v. 18, n. 1, 2013. 
GIL, A. C. Métodos e técnicas de pesquisa social. São Paulo: Atlas, 6ạ Edição, 2010.

MONTEIRO, J.H.P. et al. Manual de Gerenciamento Integrado de resíduos sólidos. Coordenação técnica Victor ZularZveibil. Rio de Janeiro: IBAM, 2001.

MORESCHI, C. et al. Homenagem a Florence Nightingale e compromisso com a sustentabilidade ambiental. Rev BaianaEnferm.2011;25(2):203-8.

MOURA, A. de; VIRIATO, A. Gestão Hospitalar. São Paulo: Manole, 2008.

MOURA, G. M. S. S. de; MEOTTI, K. Resíduos sólidos de serviços de saúde: uma fotografia do comprometimento da equipe de enfermagem. Revista gaúcha de enfermagem. Porto Alegre. Vol. 32, n. 2 (jun. 2011), p. 338-344, 2011.

NAIME, R.; RAMALHO, A. H. P.; NAIME, I. S. Avaliação do sistema de gestão dos resíduos sólidos doHospital de Clínicas de Porto Alegre. Revista Espaço para a Saúde, Londrina, v.9, n.1, p.1-17, dez.2008.

OLIVEIRA, J. M. de. Análise do Gerenciamento de Resíduos de Serviços de Saúde nos Hospitais dePorto Alegre. Dissertação (Mestrado em Administração)- Universidade Federal do Rio Grande do Sul, Porto Alegre, 2002.

PEREIRA, A. L.; PEREIRA, S. R. A cadeia de logística reversa de resíduos de serviços de saúde dos hospitais públicos de Minas Gerais: análise a partir dos conceitos da nova Política Nacional de Resíduos Sólidos Urbanos. Desenvolvimento e Meio Ambiente, v. 24, 2011.

PEREIRA, S.S.; LUCENA, L. L.; FERNANDES, A. Resíduos de serviço de saúde em um hospital de Campina Grande/PB: gestão e percepção ambiental. Revista Brasileira de Gestão e Desenvolvimento Regional, v.6, n.3, p. 255-286, set.-dez./2010.

SEVERINO, A. J. Metodologia do trabalho científico. São Paulo: Cortez, 23a Edição, 2007.

SILVA, C. E., HOPPE, A. E. Diagnóstico dos resíduos de serviços de saúde no interior do Rio Grande do Sul. Artigo técnico apresentado a Revista de Engenharia Sanitária e Ambiental, v. 10, p. 146-151, 2005.

SILVA, N. M. da; RAMPELOTTO, E. M.. Segregação dos Resíduos Sólidos Hospitalares. Revista Monografias ambientais. v.5, n. 5, p. 1174-1183, 2012.

STAKE, R. E. The case study method in social inquiry. Educational researcher, v. 7, n. 2, p. 5-8, 1978. Disponível em: <http://journals.sagepub.com/doi/abs/10.3102/0013189X007002005?journalCode=edra>. Acesso em: 31 de jul. de 2018.

TAPIA, C. E. V. Diabetes mellitus e o descarte de seringas e agulhas. Rev. Gaúcha Enferm. 2009;30(2):228-34.

VILELA-RIBEIRO, E. B. et al. Uma abordagem normativa dos resíduos sólidos de saúde e a questão ambiental. REMEA - Revista Eletrônica do Mestrado em Educação Ambiental, v. 22, 2009. 